\title{
Vibration-Based Diagnostics of Steam Turbines
}

\author{
Tomasz Gałka \\ Institute of Power Engineering, \\ Poland
}

\section{Introduction}

Of three general maintenance strategies - run-to-break, preventive maintenance and predictive maintenance - the latter, also referred to as condition-based maintenance, is becoming widely recognized as the most effective one (see e.g. Randall, 2011). To exploit its potential to the full, however, it has to be based on reliable condition assessment methods and procedures. This is particularly important for critical machines, characterized by high unit cost and serious consequences of a potential failure. Steam turbines provide here a good example.

In general, technical diagnostics may be defined as determining technical condition on the basis of objective methods and measures. The objectivity implies that technical condition assessment is based on measurable physical quantities. These quantities are sources of diagnostic symptoms. For any given class of objects, the development of technical diagnostics essentially involves four principal stages (Crocker, 2003), namely:

- measurement,

- qualitative diagnostics,

- quantitative diagnostics,

- prognosis (forecasting).

At the measurement stage we are able to measure physical quantities relevant to the object technical condition. On the basis of measurement data, at the qualitative diagnostics stage faults and malfunctions are identified and located with the aid of an appropriate diagnostic model. Quantitative diagnostics consists in estimating damage degree (advancement), for which a reference scale is necessary. Finally, prognosis is an estimation of the period remaining until an intervention is needed. Qualitative diagnostics may be viewed as being aimed at detecting hard (random) failures, while the aim of the quantitative diagnosis is to trace the soft (natural) fault evolution (Martin, 1994).

Complex objects, like steam turbines, are characterized by a number of residual processes (such as vibration, noise, heat radiation etc.) that accompany the basic process of energy transformation, and hence a number of condition symptom types. For all rotating machines, vibration-based symptoms are the most important ones for technical condition assessment, due to at least three reasons:

- high content of information,

- comparatively easy and non-intrusive measurement techniques,

- $\quad$ well-developed methods for data processing and diagnostic information extraction. 
Of all vibration-based symptom types (see e.g. Morel, 1992; Orłowski, 2001), three are of particular importance for steam turbine diagnostics:

- absolute vibration spectra,

- relative vibration vectors,

- time evolution of spectral components.

These symptoms form the basis of diagnostic reasoning in both permanent (on-line) and intermittent (off-line) monitoring systems.

\section{Vibration generation and vibrodiagnostic symptoms}

Just like all rotating machines, steam turbines generate broadband vibration, so that power density spectra typically contain a number of distinct components. Due to different vibration generation mechanisms involved, it is convenient to divide the entire frequency range under consideration (typically from a few hertz up to some 10 to 20 kilohertz) into two sub-ranges, commonly referred to as the harmonic (or 'low') and blade (or 'high') frequency ranges, respectively. Sometimes the sub-harmonic range (below the fundamental frequency $f_{0}$ resulting from rotational speed) is also distinguished. This division is shown schematically in Fig.1.

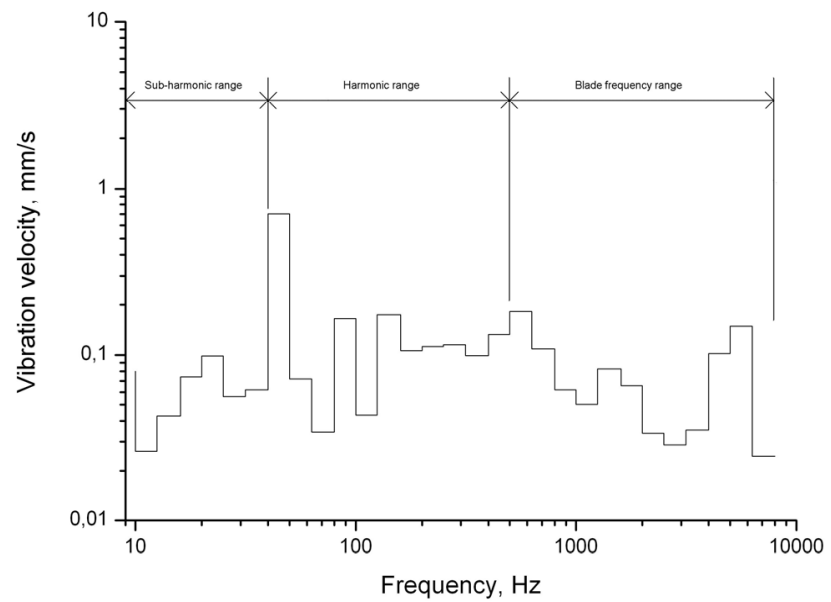

Fig. 1. Schematic representation of dividing the entire power density spectrum frequency range into sub-harmonic, harmonic and blade frequency ranges (after Gałka, 2009a).

Components from the harmonic range result directly from the rotary motion of turbine shaft and are related to malfunctions common to all rotating machines, such as:

- unbalance,

- shafts misalignment,

- bent or cracked rotors,

- magnetic phenomena in the generator.

Components that fall into the sub-harmonic range are typically determined mainly by the stability of the oil film in shaft bearings (Bently and Hatch, 2002; Kiciński, 2006). Those of 
very low frequencies (a few hertz) may be indicative of cracks in turbine casings and other non-rotating elements.

Individual components from the blade frequency range are produced as a result of interaction between steam flow and the fluid-flow system, and hence may be considered specific to steam turbines. There are three basic phenomena involved (Orłowski, 2001; Orłowski and Gałka, 1998), namely:

- flow disturbance caused by stationary and rotating blades edges,

- $\quad$ flow disturbance resulting from scatter of fluid-flow system elements dimensions.,

- flow disturbance by control valves opening.

First of these can be described in the following way: discharge edges of stationary and rotating blades introduce local interruptions of steam flow, thus reducing its thrust on a rotating blade and causing an instantaneous force of the opposite direction. Resulting force $q_{1}$ is thus periodic and can be expressed by

$$
q_{1}=\zeta_{0}+\Sigma \zeta_{k} \cos k\left(n \omega t+\Psi_{k}\right)
$$

where $\zeta_{0}$ is time-averaged thrust, $\zeta_{k}$ and $\Psi_{k}$ are amplitude and phase of the $k$-th component, respectively, $n$ is number of blades in a stage (stationary or rotating) under consideration and $\omega$ denotes angular frequency. This force can thus be expressed as a series of harmonic components with frequencies equal to $k n \omega=2 \pi k n u$, where $u$ is the rotational speed in $\mathrm{s}^{-1}$. As for the second phenomenon, it results from the fact that manufacture of blades and their assembly into rotor stages or bladed diaphragms are not perfect, so for each blade the corresponding discharge cross-section is slightly different from the other ones. Resulting force has a form of a pulse generated once per rotation and thus may be expressed by

$$
q_{2}=\zeta_{0}+\Sigma \zeta_{k} \cos k\left(\omega t+\Psi_{k}\right)
$$

The third phenomenon is related to turbine control and shall be dealt with a little later. It should be mentioned, however, that - unlike the first two - the influence of control valves opening is usually limited to the vicinity of the control stage and diminishes as we move along the steam expansion path. Frequencies of basic spectral components resulting from interaction between steam flow and the fluid-flow system can be, on the basis of above considerations, expressed by

$$
\begin{gathered}
f_{w}=l \cdot u \\
f_{k}=b \cdot u \\
f_{(w+k) / 2}=(l+b) \cdot u / 2 \\
f_{(w-k) / 2}=(l-b) \cdot u / 2
\end{gathered}
$$

where $l$ and $b$ denote numbers of blades in rotor stages and bladed diaphragms, respectively. Components given by Eqs.(5) and (6) result from interactions between rotor stages and adjacent bladed diaphragms. Each turbine stage is thus in general characterized by as many as six individual vibration components. 
Vibration signal that can be effectively measured in an accessible point of a turbine is influenced not only by relevant generation mechanisms, but also by its propagation to this point, as well as by operational parameters and interference (see e.g. Radkowski, 1995; Gałka, 2011b). In general terms it may be expressed as (Radkowski, 1995)

$$
z(r, t)=h_{p}(r, t) * u_{w}(r, t)+\eta(r, t)
$$

where $z$ denotes measured diagnostic signal, $h_{p}$ is the response function for signal propagation from its origin to the measuring point and $\eta$ denotes uncorrelated noise; all these quantities are functions of the spatial variable $r$ and dynamic time $t . u_{w}(r, t)$ is given by

$$
u_{w}(r, t)=\sum_{i=1}^{n} h_{i}\left(r, D_{i}, t\right) * x(t)+h(r, t) * x(t)
$$

where $D_{i}$ describes development of the $i$ th defect, $h_{i}$ is the response function pertaining to this defect and $h$ is the response function with no defect present; $x(t)$ is the input signal, generated by an elementary vibroacoustic signal source. This model is shown schematically in Fig.2.

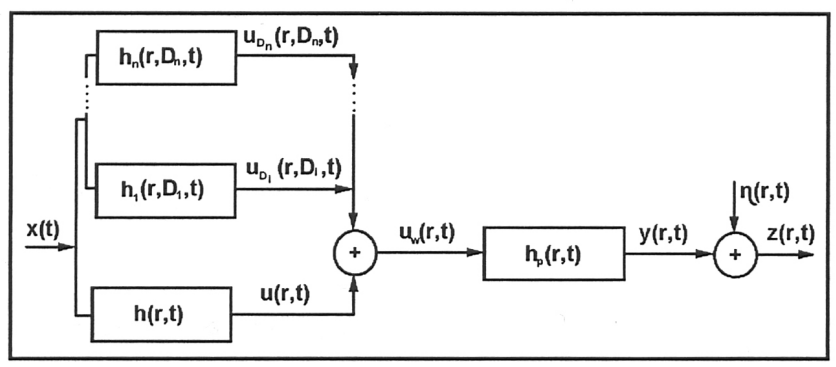

Fig. 2. Model of vibroacoustic signal generation and propagation (after Radkowski, 1995).

An alternative general relation, in a vector form, is provided by (Orłowski, 2001)

$$
\mathbf{S}(\theta)=\mathbf{S}[\mathbf{X}(\theta), \mathbf{R}(\theta), \mathbf{Z}(\theta)],
$$

where $\mathbf{S}, \mathbf{X}, \mathbf{R}$ and $\mathbf{Z}$ denote vectors of symptoms, condition parameters, control parameters and interference, respectively, all varying with time $\theta .{ }^{1}$ Control parameters may be defined as resulting from object operator purposeful action, aimed at obtaining demanded performance (Gałka, 2011b). In steam turbines, usually (at least in power industry) the 'demanded performance' means demanded output power; active load $P_{u}$ can thus be treated as a scalar measure of the vector $\mathbf{R}$. As for the interference, two types can be distinguished: external interference (the source is outside the object) and internal interference (the source is within the object). With some reservations, the former can be identified with measurement errors, while the latter refers to all other contributions to the uncorrelated noise $\eta(t)$ in Eq.(7).

\footnotetext{
${ }^{1}$ The reason for using $t$ and $\theta$ symbols for denoting time is that the former refers to the 'dynamic' time (e.g. that enters equations of motion), while the latter is for the 'operational' time - the argument of equations pertaining to technical condition evolution.
} 
Let us assume that the influence of interference may be reduced to a point wherein it can be neglected. As control parameters are, at any given moment, known, there is obviously a possibility of symptom normalization with respect to them, either model-based or empirical. It has to be kept in mind, however, that normalization with respect to $P_{u}$, which seems most straightforward, in practice may be only approximate. $P_{u}$ can be expressed as (Traupel, 2000)

$$
P_{u}=(d m / d t) \Delta i \eta_{t},
$$

where $d m / d t$ denotes steam mass flow, $\Delta i$ is the enthalpy drop and $\eta_{t}$ is the turbine efficiency. Assuming that $\eta_{t}$ remains constant (which is only an approximation), $P_{u}$ may be controlled by changing $\Delta i$ (qualitative control), $d m / d t$ (quantitative control), or both. The latter method (known as group or nozzle control) is typically used in large steam turbines. Each control valve supplies steam to its own control stage section; the number of these valves in large steam turbines is usually from three to six and they are opened in a specific sequence. At the rated power the last valve is only partly open, or even almost closed, as it provides a reserve in a case of a sudden drop of steam parameters. Furthermore, $\Delta i$ depends also on condenser vacuum, which for a given unit may change within certain limits depending on overall condenser condition, cooling water temperature, weather etc. Thus

$$
P_{u}=f\left(r_{1}, r_{2}, \ldots, r_{k}, p_{0}\right) \text {, }
$$

where $r_{i}$ denotes $i$ th valve opening, $k$ is the number of valves and $p_{o}$ is the condenser pressure. In fact, $r_{i}$ and $p_{o}$ are the $\mathbf{R}(\theta)$ vector parameters, various combinations of which may yield the same value of $P_{u}$. In view of Eqs.(9) and (11), any $S_{i}\left(P_{u}\right)$ function $\left(S_{i} \in \mathbf{S}\right)$ cannot thus be a single-valued one.

Some attention has been paid to developing experimental relations of the $S_{i}=f\left(P_{u}\right)$ type (see e.g. Gałka, 2001), bearing in mind that they are approximate and applicable to a given turbine type only. Such relations turn out to be strongly non-linear and differences between individual symptoms are considerable. In general, within the load range given by roughly $P_{u}=(0.85 \div 1.0) P_{n}$, where $P_{n}$ is rated power, variations are quite small; thus, when dealing with large sets of data, the simplest approach is to reject those acquired at extremely low or high loads. It has to be added that the fact of vibration-based symptoms dependence on control parameters and interference may serve as a basis for developing certain diagnostic procedures; this issue shall be dealt with in Section 6.

\section{Qualitative diagnosis}

As already mentioned, qualitative diagnosis consists in determining what malfunctions or damages are present and localizing them. In this Section the influences of control and interference shall be neglected, i.e. it shall be assumed that symptoms under consideration are deterministic functions of condition parameters $X_{i} \in \mathbf{X}$.

For obvious reasons, the following review does not claim to be exhaustive and is concentrated on issues relevant to steam turbine applications. For comprehensive and detailed treatment the reader is referred e.g. to (Morel, 1992; Bently and Hatch, 2002; Randall, 2011). 


\subsection{Harmonic (low) frequency range}

Basically this subsection deals with absolute vibration spectral components of frequencies determined by $f=n f_{0}$, where $f_{0}$ results from rotational speed, and to some extent also with relative vibration vectors or orbits. In practical applications, components corresponding to $n>4$ are seldom accounted for; this means that we are dealing with first four harmonic and sub-harmonic $(n<1)$ components. As each of these is typically influenced by a number of condition parameters, it is convenient to speak in terms of possible malfunctions and faults rather than frequencies.

\subsubsection{Unbalance}

Unbalance is common to all rotating elements. Primary symptom of this malfunction is the $1 \times f_{0}$ component of absolute vibration in a direction perpendicular to the turbine shaft line. They are, however, many other possible malfunctions (some of them quite common) that produce similar vibration patterns; additional procedures are therefore usually needed for a correct diagnosis.

In general, a 'pure' unbalance, be it static, quasi-static or dynamic, produces a $1 \times f_{0}$ component that remains almost constant in amplitude and phase during steady-state operation and disappears at low rotational speed. As rotor systems are non-linear, this component is typically accompanied by higher harmonics $(n>1)$, with amplitudes decreasing as $n$ increases. Shaft orbits usually are quite regular and nearly circular or slightly elliptical. If such vibration pattern is present, the probability of unbalance being the root cause is high. Proper rotor balancing will usually reduce the residual unbalance to an acceptable level.

Rotor systems will always respond to balancing. Step changes of the $1 \times f_{0}$ component not related to any maintenance activities (but occurring mainly after turbine shutdown and subsequent startup) may be indicative of a loose rotor disk. Similarly, sudden and dramatic change may result from a broken rotor blade; such step changes are often big enough to enforce turbine tripping. Much slower, but continuous increase is often indicative of a permanent rotor bow (see also sub-section 3.1.3). An example is shown in Fig.3; it is easily

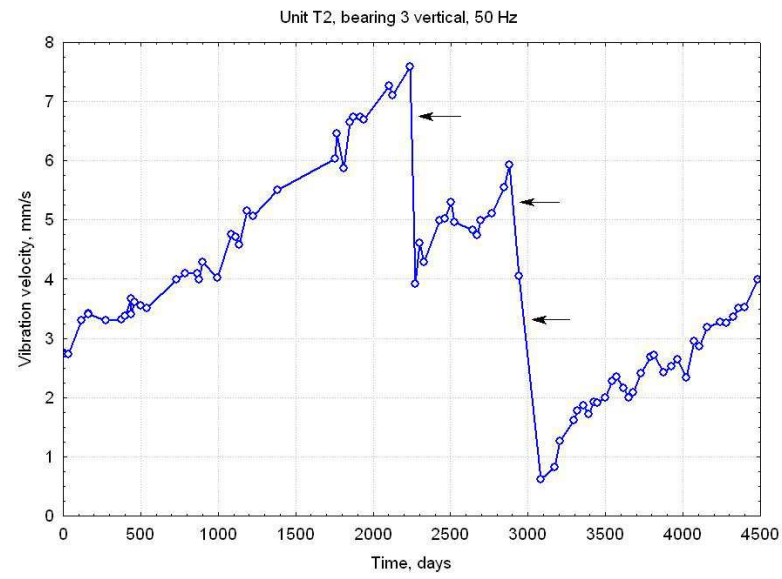

Fig. 3. Time history of the $1 \times f_{0}$ component with permanent rotor bow present: $230 \mathrm{MW}$ unit, rear intermediate-pressure turbine bearing, vertical direction. Arrows indicate balancing sessions. 
seen that balancing results in a considerable decrease of the $1 \times f_{0}$ component, but the improvement is only temporary. If this component is comparatively high at low rotational speed, coupling problem (offset rotor axles) is a possible root cause, especially in turbines with rigidly coupled rotors.

\subsubsection{Misalignment}

Ideally the entire turbine-generator unit shaft line (with overall length approaching $70 \mathrm{~m}$ in large units in nuclear power plants) should be a continuous and smooth curve; a departure from such condition is referred to as misalignment. The shape of this line is determined by shaft supports (journal bearings). As they displace during the transition from 'cold' to 'hot' condition, due to changing temperature field (this process may take even a few days to complete), at the assembly stage care has to be taken to ensure that the proper shape is maintained during normal operation. Relative vertical displacements may be even of the order of millimeters (Gałka, 2009a).

Misalignment modifies distribution of load between individual shaft bearings and therefore affects shaft orbits. With increasing misalignment magnitude they typically evolve from elongated elliptical shape through bent ('banana') and finally to highly flattened one (Bently and Hatch, 2002). High misalignment may lead to oil film instability, but in large steam turbines (especially modern ones, with only one bearing per coupling) this is a very rare occurrence. As for absolute vibration, $2 \times f_{0}$ component in directions perpendicular to the turbine axis is generally recognized as the basic misalignment symptom. Care, however, has to be taken when dealing with the turbine-generator coupling, as this component may be dominated by the influence of the generator (asymmetric position of rotor with respect to the stator electromagnetic field); in the latter case, dependence on the excitation current is usually conclusive. Marked misalignment is often accompanied with relatively high amplitudes of harmonic components in axial direction, but this symptom can by no means be considered specific.

\subsubsection{Rotor bow}

In general, three types of turbine rotor bow can be distinguished, namely:

- elastic bow, resulting from static load,

- temporary bow, caused by uneven temperature field and/or anisotropic rotor material properties, and

- permanent bow, wherein material yield strength has been exceeded (plastic deformation).

Permanent bow is obviously the most serious one. As it causes the center of gravity to move off from the shaft centerline, it basically produces an unbalance (cf. Fig.3). In general, rotor response vector may be expressed as (Bently and Hatch, 2002):

$$
\mathbf{r}=r_{e} e^{j \delta}+\frac{M r_{e} \omega^{2} e^{j \delta}}{\left[K-M \omega^{2}+j D(1-\lambda) \omega\right]},
$$

where $M$ denotes unbalance mass, shifted at the distance $r_{e}$ in the direction determined by the angle $\delta . K$ and $D$ are stiffness and damping coefficients, respectively; $\omega$ denotes rotor 
angular velocity and $\lambda$ is the fluid circumferential velocity ratio $(\lambda=v / \omega$, where $v$ denotes average fluid angular velocity). First term describes the low-speed response (which, as mentioned earlier, is basically absent with 'plain' unbalance), while the second one refers to the dynamic synchronous response. It can be seen that for $\omega>>\omega_{r}$ (where $\omega_{r}$ is the resonance angular speed), when the first and the third term in the denominator can be neglected, rotor response is close to zero. This is a feature characteristic for this malfunction (colloquially speaking, the rotor 'balances itself out'), but in large steam turbines with heavy flexible rotors the $\omega>\omega_{r}$ condition is seldom fulfilled.

It has been shown (Gałka, 2009b) that permanent rotor bow causes simultaneous increase of the $1 \times f_{0}$ component in vertical and axial directions, so that a developing bow should result in strong correlation between these components (see also Section 6). Available data seem to confirm this conclusion, in fact based on quite simple model considerations.

\subsubsection{Rotor crack}

As a very serious fault with potentially catastrophic consequences, rotor crack has received considerable attention (for perhaps the most comprehensive available review, see Bachschmid, Pennacchi and Tanzi, 2010). In general, crack reduces shaft stiffness and thus causes resonance to shift to a lower rotational speed. As a result, the $1 \times f_{0}$ component amplitude during steady-state operation will either increase or decrease. In large steam turbines, operated above the first critical speed, the latter may be the case. This effect may be combined with that of increasing rotor bow due to reduced bending stiffness. As a result of asymmetry introduced by a crack, the $2 \times f_{0}$ component may also increase substantially.

It is generally recognized that considerable continuous changes of first two harmonic components amplitudes (not necessarily both increasing!) and phases during steady-state operation indicate that a shaft crack is possibly present. Rates of these changes vary within broad limits, from the order of months to days or even hours - in the latter case, a catastrophic failure is most probably imminent. Such evolution of vibration patterns should serve as an alert. Presence of a crack may be confirmed by monitoring absolute and relative vibration during transients - typically after a turbine trip. Time histories of the $1 \times f_{0}$ and $2 \times f_{0}$ components, obtained in such manner, may be compared with reference data recorded after unit commissioning or a major overhaul. Significant reduction of critical speeds and increase of vibration amplitudes on passing through them are indicative of this malfunction, as well as is high overall relative vibration amplitude; the latter will sometimes render the startup impossible to complete, as the unit shall be tripped automatically below nominal rotational speed.

\subsubsection{Bearing problems}

A problem specific to shaft journal bearings is oil film instability that induces so-called selfexcited vibrations. This issue has attracted considerable attention and detailed theoretical models have been developed (Bently and Hatch, 2002; Kiciński, 2006). It can be shown that threshold rotational speed for the onset of instability $\Omega_{\text {th }}$ is given by

$$
\Omega_{t h}=\frac{1}{\lambda} \sqrt{\frac{K}{M}}
$$


where $K$ and $M$ denote stiffness and mass, respectively, and $\lambda$ is the oil circumferential velocity ratio. It is therefore obvious that a suitable stability margin should be provided by proper design and operation, which influence all three quantities that determine $\Omega_{t h}$.

Bearing instability is nicely demonstrated with laboratory-scale model rotor systems. For large steam turbines in power industry, operated at a fixed rotational speed, this is a rare occurrence. Most frequently it results from bearing vertical displacement, due to thermal deformation and/or foundation distortion. Downward displacement reduces bearing load and causes $K$ to decrease, so that $\Omega_{\text {th }}$ may become lower than the nominal rotational speed. In such circumstances, instability is unavoidable. Most typical symptom of this malfunction is the increase of sub-harmonic spectral components, often of the 'hump' shape centered slightly below $0.5 \times f_{0}$. Shaft orbits typically exhibit loops. Strong instability results in high relative vibration that leads to bearing damage. Proper adjustment of bearing positions is the primary action to be taken; sometimes reduction of the bearing size (length), in order to increase specific load, is necessary for a permanent remedy (Orłowski and Gałka, 1995).

Due to strong non-linearity, journal bearings generate higher harmonic components which may be very sensitive to bearing condition, clearances and oil pressure. An example is shown in Fig.4, in the form of a time history of the $3 \times f_{0}$ absolute horizontal vibration component. Initially very low, it increased dramatically following a minor bearing damage and remained at a high level, exhibiting considerable variations that suggest a resonance nature of the phenomenon. Permanent improvement was achieved only after a major overhaul. It has to be noted that such behavior is to a large extent influenced by design features; therefore care has to be taken when generalizing the results over other turbine types. In any case, sensitivity of spectral components to oil pressure is decisive.

Typical malfunctions which have their representations in the low frequency range and their corresponding symptoms have been listed in Table 1, which summarizes this subsection.

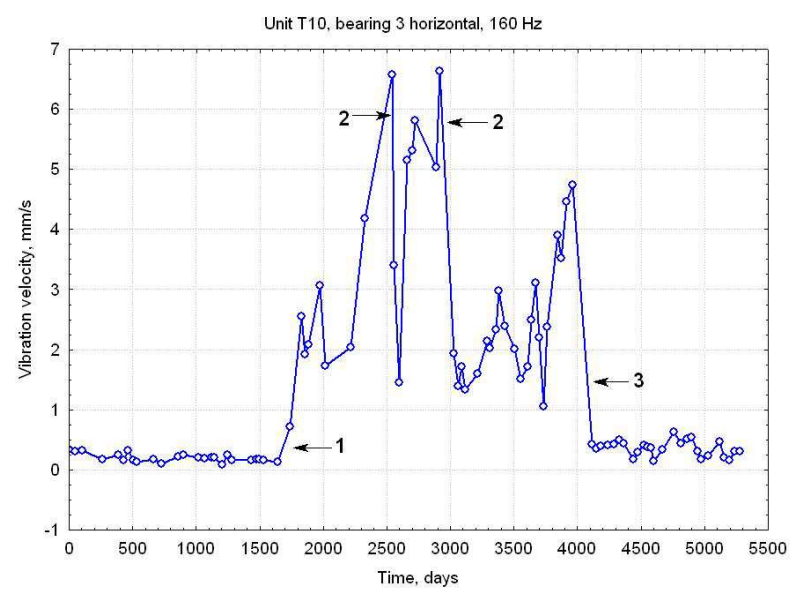

Fig. 4. Time history of the $3 \times f_{0}$ component: $200 \mathrm{MW}$ unit, rear intermediate-pressure turbine bearing, horizontal direction. Arrows: 1, bearing damage; 2, bearing position and clearances adjustments; 3 , major overhaul 


\begin{tabular}{|c|l|}
\hline Malfunction & \multicolumn{1}{|c|}{ Typical symptoms } \\
\hline Unbalance & $\begin{array}{l}1 \times f_{0} \text { component in vertical and horizontal directions, constant } \\
\text { amplitude and phase, decreasing at low rotational speed }\end{array}$ \\
\hline Misalignment & $\begin{array}{l}2 \times f_{0} \text { component in vertical and horizontal directions, 'banana- } \\
\text { shaped' or flattened shaft orbits, high harmonic components in axial } \\
\text { direction }\end{array}$ \\
\hline Permanent rotor bow & $\begin{array}{l}1 \times f_{0} \text { component in vertical and horizontal direction (also at low } \\
\text { rotational speed), strong correlation between } 1 \times f_{0} \text { components in } \\
\text { vertical and axial directions, }\end{array}$ \\
\hline Rotor crack & $\begin{array}{l}\text { Continuous changes of } 1 \times f_{0} \text { and } 2 \times f_{0} \text { components amplitudes and } \\
\text { phases during steady-state operation, reduction of critical speeds } \\
\text { and increase of vibration amplitudes on passing through them }\end{array}$ \\
\hline Bearing problems & $\begin{array}{l}\text { Increase of sub-harmonic components (typically slightly below } \\
\left.0.5 \times f_{0}\right), \text { relative vibration increase, shaft orbits with loops, high and } \\
\text { unstable amplitudes of higher harmonic components, sensitive to } \\
\text { bearing oil pressure }\end{array}$ \\
\hline
\end{tabular}

Table 1. Typical steam turbine malfunctions and their representation in low-frequency vibration-based symptoms.

\subsection{Blade (high) frequency range}

So-called blade spectral components, with frequencies given by Eqs.(3) to (6), are usually low in amplitude. Typically they fall into the frequency range from a few hundred hertz to about $10 \div 20$ kilohertz. In vibration displacement spectra they are undistinguishable, so velocity or acceleration spectra have to be employed. Constant-percentage bandwidth (CPB) analysis is the most convenient tool; $23 \% \mathrm{CPB}$ yields satisfactory results.

Technical condition of the individual fluid-flow system components, i.e. rotor stages and bladed diaphragms, influences the $\zeta_{k}$ coefficients in Eqs.(1) and (2) and hence the vibration amplitudes in relevant frequency bands. Blade components are, however, highly sensitive to control and interference. Influence of control may be seen as a competition between two mechanisms. First, with nozzle control typical for large steam turbines, there is an asymmetry of steam pressure distribution over the turbine cross-section that depends on the control valve opening. This asymmetry affects forces resulting from the steam flow thrust, again via the $\zeta_{k}$ coefficients. As turbine load increases and consecutive valves are opening, pressure distribution becomes more uniform. Second, with increasing turbine load and steam mass flow, the $\zeta_{0}$ coefficient also increases. As already mentioned, it may be expected that the former mechanism shall influence vibration patterns at points close to the control stage, as the asymmetry decreases as we move downstream the steam expansion path. The latter should be noticeable for last low-pressure turbine stages, with long blades and large cross-section area. In practice, influence of steam flow asymmetry on blade components is quite strong in points located at the high-pressure turbine; operation at extremely low loads ${ }^{2}$ may cause them to increase even by a few times. Steam mass flow influence is usually much weaker.

${ }^{2}$ Load minimum is usually imposed by the steam generator (boiler or nuclear reactor) stable operation considerations. 
Fig. 5 shows relative standard deviation $(\sigma / \hat{S}$, where $\hat{S}$ denotes mean value) plotted against mid-frequency of $23 \% \mathrm{CPB}$ spectrum bands, determined for a $120 \mathrm{MW}$ steam turbine. It is immediately seen that for the harmonic range $\sigma / \hat{S}$ is below 0.1 , while in the blade range it may be as high as about 0.6 to 0.8 . Similar analysis for other turbine types has yielded quantitatively comparable results (Gałka, 2011b). In such circumstances, a time history of a blade spectral component has to be considered a monotonic curve with large fluctuations imposed; an example is shown in Fig.6. Therefore the very occurrence of a high amplitude cannot be unanimously considered as indicative of a fluid-flow system failure. From the point of view of measurement data processing, values heavily influenced by control and/or interference have to be treated as outliers.

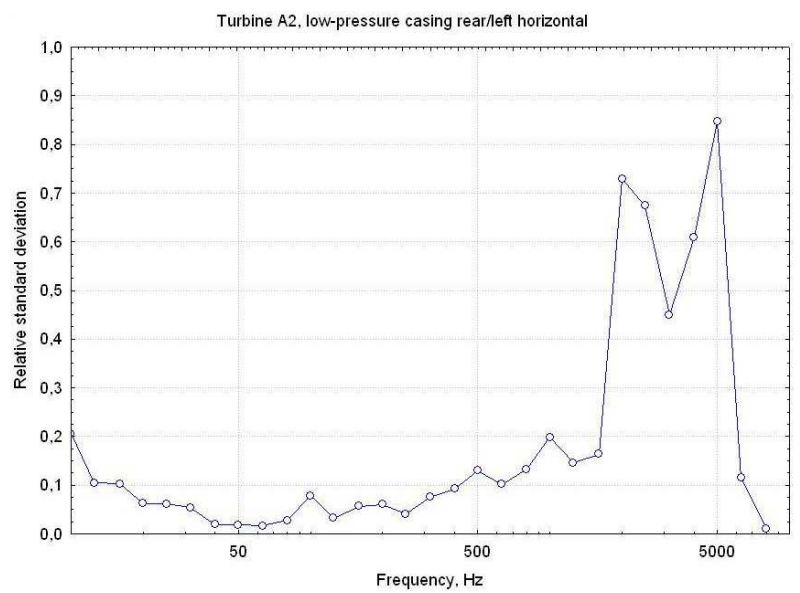

Fig. 5. Relative standard deviation vs. frequency: results for a $120 \mathrm{MW}$ unit, low-pressure turbine casing rear/left side, horizontal direction; data obtained from 90 consecutive measurements (after Gałka, 2011b).

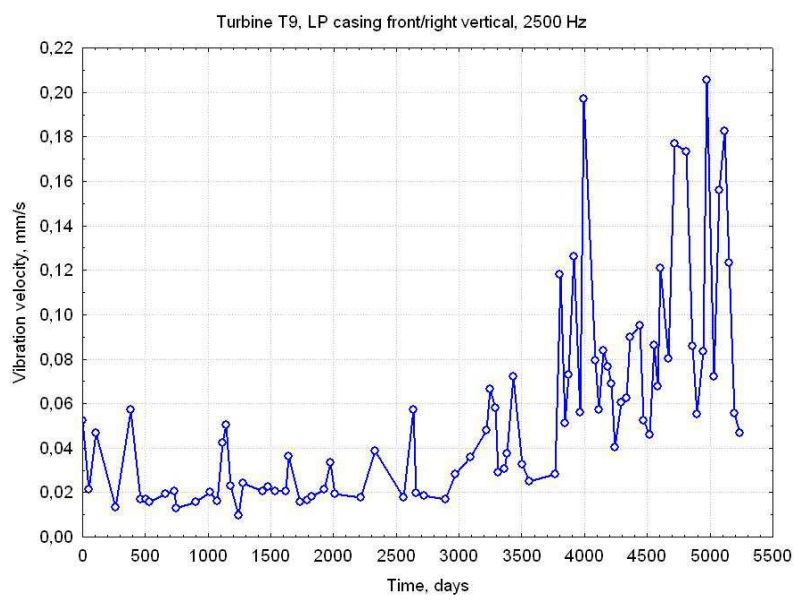

Fig. 6. Time history of the $2500 \mathrm{~Hz}$ component: $200 \mathrm{MW}$ unit, low-pressure turbine casing front/right side, vertical direction 
It has to be noted that in steam turbines there are sources other than the fluid-flow system that generate vibration components with frequencies in the same range. Typically this is the case with oil pump and governor, driven from turbine shaft via gears. If unexpectedly high amplitudes are encountered, additional narrow-band analysis provides conclusive data, as frequencies of these components may be easily calculated.

\section{Quantitative diagnosis}

In short, qualitative diagnosis provides an answer to the question 'what', while quantitative diagnosis is expected to tell 'how much'. This problem is becoming particularly important when a turbine is operated beyond its design lifetime, which is by no means uncommon. It has to be kept in mind that many turbines still in operation had been designed a few dozen years ago, with much less knowledge of lifetime consumption mechanisms and therefore larger safety margins. Quantitative diagnosis is obviously mandatory if condition-based maintenance is to be introduced.

By necessity, for a quantitative condition assessment a reference scale of some kind has to be used. Such scale may be provided by three values: basic, limit and admissible. Basic value $S_{b}$ corresponds to a new object with no malfunctions or faults present. Limit value $S_{l}$ may be considered as determining the 'normal' operation range: if $S>S_{l}$, further operation is still possible, but the machine cannot fulfill all requirements (concerning e.g. reliability, economy, output, environmental impact etc.). Admissible value $S_{a}$ is determined from safety considerations: $S>S_{a}$ indicates high possibility of imminent breakdown and should result in machine tripping.

As $S_{a}$ is in practice irrelevant to technical diagnostics and $S_{b}$ may be determined in a rather straightforward manner, the $S_{l}$ estimation is fundamental for quantitative diagnostics. A complex machine is characterized by a large number of symptoms, and obviously each of them may be assigned its specific limit value. An approach to this estimation is provided by the Energy Processor model and the concept of symptom reliability (for a comprehensive and detailed treatment, see Natke and Cempel, 1997). This approach is based on the fact that any energy-transforming object is a source of residual processes, such as vibration, noise, thermal radiation etc. The power of these processes $V$ can be shown to depend on the object condition. In the simplest case the relation is given by

$$
V=V_{0}\left(1-\frac{\theta}{\theta_{b}}\right)^{-1}
$$

where $V_{0}=V(\theta=0)$ and $\theta_{b}$ denotes time to breakdown, determined by the time-invariant properties of the object. As Eq.(14) has been derived with quite restrictive assumptions, several modifications have been proposed, applicable for various types of diagnostic objects (see e.g. Gałka and Tabaszewski, 2011); they inevitably result in considerable complication of the mathematical description.

In practice $V$ is usually non-measurable and accessible only via measurable symptoms. A symptom is related to $V$ by so-called symptom operator $\Phi$. Several types of symptom operators have been proposed (see e.g. Natke and Cempel, 1997). In steam turbine applications, Weibull and Fréchet operators have been found particularly appropriate; it also has to 
be added that they conform to all relevant requirements (in particular, vertical asymptote at $\theta=\theta_{b}$ ), while some other operators (e.g. Pareto or exponential) are valid only for small values of $\theta / \theta_{b}$. Weibull operator results in the following expression for a symptom as a function of $\theta$.

$$
S(\theta)=S_{0}\left(\ln \frac{1}{1-\theta / \theta_{b}}\right)^{1 / \gamma}
$$

while Fréchet operator yields:

$$
S(\theta)=S_{0}\left(-\ln \theta / \theta_{b}\right)^{-1 / \gamma}
$$

In both cases, $\gamma$ is the shape factor to be determined empirically and $S_{0}=S(\theta=0)$.

In order to determine $S_{l}$, the concept of symptom reliability is introduced. Symptom reliability $R(S)$ is defined (Cempel, Natke and Yao, 2000) as the probability that a machine classified as being in good condition $\left(S<S_{l}\right)$ will remain in operation with the symptom value $S<S_{b r}$, where $S_{b r}$ denotes value corresponding to breakdown. This may be written as

$$
R(S) \equiv \mathrm{P}\left(S_{b r}>S \mid S<S_{l}\right)
$$

Analytically this may be expressed as

$$
R(S)=\int_{S}^{\infty} p\left(S^{*}\right) d S^{*} .
$$

where $p(S)$ denotes the symptom probability density function. Determination of the limit value must involve some measure of acceptable operational risk. This may be accomplished by using the Neyman-Pearson rule, known from statistical decision theory (Neyman and Pearson, 1933). In this particular case, it yields

$$
R\left(S_{l}\right) \cdot G=G \int_{S_{l}}^{\infty} p(S) d S=A,
$$

where $G$ denotes the availability of the machine (or group of machines) and $A$ is the acceptable probability of erroneous condition classification as 'faulty', i.e. performing an unnecessary repair.

For a given symptom operator, $p(S)$ may be estimated from experimental data, providing that the available database is sufficiently large. In practice (Gałka, 1999) about 100 individual data points will allow for a reasonable estimation. Weibull and Fréchet operators usually yield $S_{l}$ values differing just by a few percent.

A set of limit values should be considered specific for a given turbine example; experience has shown that generalization of results over the entire type should be avoided. It has to be kept in mind that an overhaul often results in a considerable modification of vibration characteristics. This refers mainly to harmonic components, which are sensitive even to minor repairs or adjustments, while blade components are typically influenced only by 
major overhauls that involve opening of turbine casings. Formally such overhaul is equivalent to creating a new object. Normalization of the influence of overhauls (which determine machine life cycles) is quite straightforward if $S_{0}$ values are available, which is usually the case.

\section{Evolutionary symptoms}

Insofar attention has been focused on vibration characteristics recorded at some given moment $\theta$. Diagnostic information is obviously also contained in symptom time histories. Although state-of-the-art vibration monitoring systems facilitate so-called trending, i.e. plotting of $S$ against $\theta$, this is seldom used for diagnostic purposes. It has to be mentioned that this refers to steady-state operation data, not transients (startups or shutdowns). In general, any quantity pertaining to the $S(\theta)$ time history may be evaluated in terms of diagnostic reasoning and treated as a symptom itself.

Time histories of vibration components, especially in the blade frequency range, are usually quite irregular. As already mentioned, symptom time history may be considered a monotonic trend with superimposed fluctuations resulting from control and interference (cf. Eq.(9)). If a fault develops fast and strongly influences vibration patterns, this trend is clearly visible (see Fig.3). On the other hand, if condition evolution is slow, it may be suppressed by control and interference to a point where it is barely distinguishable. The latter is often the case for the blade frequency range. Various data smoothing procedures have been proposed to extract the monotonic trend, including three-point averaging, wherein $k$ th symptom reading $S\left(\theta_{k}\right)$ is replaced with $S^{\prime}\left(\theta_{k}\right)$ given by:

$$
S_{i}^{\prime}\left(\theta_{k}\right)=\frac{1}{3}\left[S_{i}\left(\theta_{k-1}\right)+S_{i}\left(\theta_{k}\right)+S_{i}\left(\theta_{k+1}\right)\right]
$$

Another option is peak trimming, which in fact consists in eliminating isolated outliers. This method is based on the assumption that if

$$
S\left(\theta_{k}\right) / S\left(\theta_{k-1}\right)>c \text { and } S\left(\theta_{k}\right) / S\left(\theta_{k+1}\right)>c,
$$

then the $S\left(\theta_{k}\right)$ value is suspicious and treated as an outlier; in such cases, $S\left(\theta_{k}\right)$ is replaced by $S^{\prime}\left(\theta_{k}\right)=\left[S\left(\theta_{k-1}\right)+S\left(\theta_{k+1}\right)\right] / 2$. For steam turbines $c=1.5$ is reasonable.

Six basic types of vibration evolution can be distinguished for rotating machines in general (Morel, 1992), namely:

- $\quad$ simple evolution (linear or nearly linear),

- complex evolution (usually variations or fluctuations superimposed on a monotonically increasing curve),

- stepwise changes (discontinuous evolution),

- exponential increase,

- cyclic or nearly cyclic variations,

- rapid random variations.

Moreover, each type is characterized by a 'timescale' ranging within broad limits, from seconds to years. Both evolution type and timescale depend on the malfunction or damage 
type and on the turbine element involved, so the primary idea was to employ this approach in qualitative diagnostics. General guidelines for steam turbines are given in Table 2 (after Orłowski, 2001).

Vibration evolution assessment is, however, far more important for a quantitative diagnosis. If we limit our attention to Weibull and Fréchet operators, we may expand relevant expressions for $S(\theta)$ into Taylor series around $\theta / \theta_{b}=a$, wherein $0<a<<1$ (for mathematical reasons, $a=0$ is unacceptable). Truncating higher-order terms, we obtain $S(\theta)$ in the form of

$$
S(\theta) \cong S_{0}\left(1+A \frac{\theta}{\theta_{b}}\right),
$$

which is valid for $\theta<<\theta_{b}$. The constant $A$ depends on the symptom operator and is given by

$$
A=\frac{1}{\gamma(1-a)}\left(\ln \frac{1}{1-a}\right)^{1 / \gamma-1}
$$

\begin{tabular}{|c|c|c|}
\hline Evolution type & Timescale & Failure \\
\hline \multirow[b]{2}{*}{$\begin{array}{c}\text { Simple (linear or nearly linear } \\
\text { increase) }\end{array}$} & over $24 \mathrm{~h}$ & deformation of casings \\
\hline & $\begin{array}{l}\text { a few minutes to a few } \\
\text { hours }\end{array}$ & $\begin{array}{l}\text { deformation of rotors, } \\
\text { thermal unbalance } \\
\text { (temporary) }\end{array}$ \\
\hline \multirow{3}{*}{$\begin{array}{l}\text { Complex (usually fluctuations } \\
\text { superimposed on an increasing } \\
\text { trend) }\end{array}$} & $\begin{array}{l}\text { a few minutes to a few } \\
\text { hours }\end{array}$ & $\begin{array}{l}\text { thermal unbalance } \\
\text { (temporary) }\end{array}$ \\
\hline & a few hours to a few days & $\begin{array}{l}\text { variations of natural } \\
\text { frequencies }\end{array}$ \\
\hline & a few days to a few months & $\begin{array}{l}\text { deformation of casings } \\
\text { and/or foundations }\end{array}$ \\
\hline Stepwise (discontinuous) & a few seconds & $\begin{array}{c}\text { damage of blades, } \\
\text { cracks of rotor elements }\end{array}$ \\
\hline \multirow{2}{*}{$\begin{array}{l}\text { Exponential or nearly } \\
\text { exponential }\end{array}$} & $\begin{array}{c}\text { a few to a few dozen } \\
\text { minutes }\end{array}$ & rubbing in labyrinth seals \\
\hline & a few hours to a few weeks & material creep effects \\
\hline \multirow{2}{*}{ Cyclic or nearly cyclic } & variable & soft rubbing in seals \\
\hline & a period of a few seconds & flutter, problems with control \\
\hline Rapid random & & $\begin{array}{l}\text { bearing instability, } \\
\text { steam flow instability }\end{array}$ \\
\hline
\end{tabular}

Table 2. Failures and damages of steam turbines revealed in vibration evolution parameters (after Orłowski, 2001)

for the Weibull operator and

$$
A=\frac{1}{\gamma a}(-\ln a)^{-(1 / \gamma+1)}
$$

for the Fréchet operator. We may thus infer that, if lifetime consumption (given by $\theta / \theta_{b}$ ) is small, symptom time history will be well approximated by a straight line and its slope will 
not change substantially with time. In fact this is compatible with the main mechanisms of lifetime consumption, i.e. fatigue and creep, for which linear approximations for $\theta<<\theta_{b}$ are also valid. Such case is illustrated by an example shown in Fig.7a. On the other hand, for a considerable lifetime consumption, the slope will initially increase with time (Fig.7b) to a point wherein linear approximation is no longer acceptable and $S(\theta)$ resembles an exponential curve. For $\theta$ close to $\theta_{b}$ even exponential fit fails (Fig.7c).

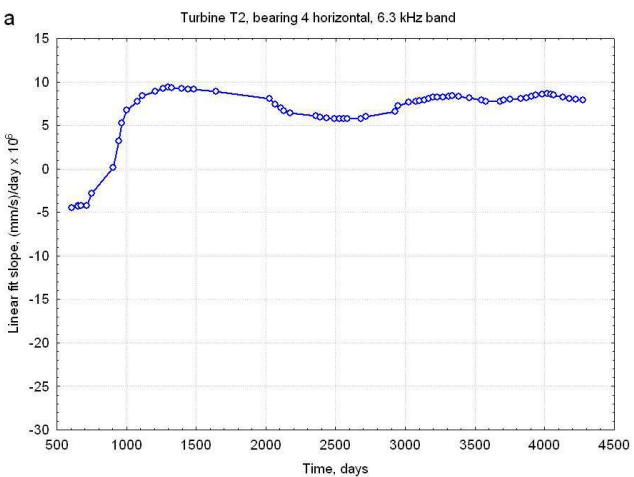

(a)

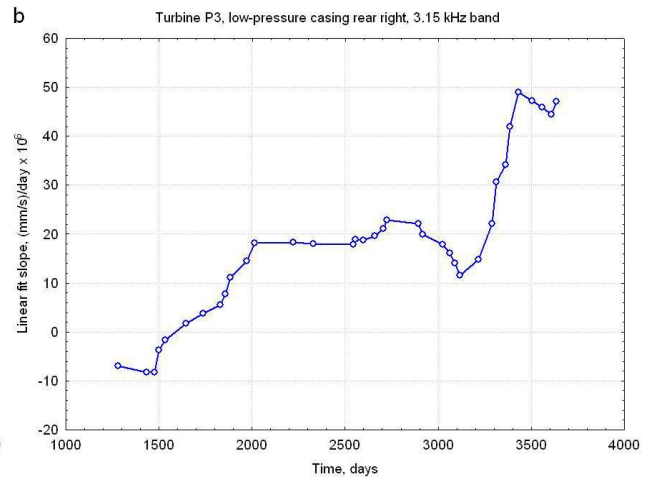

(b)

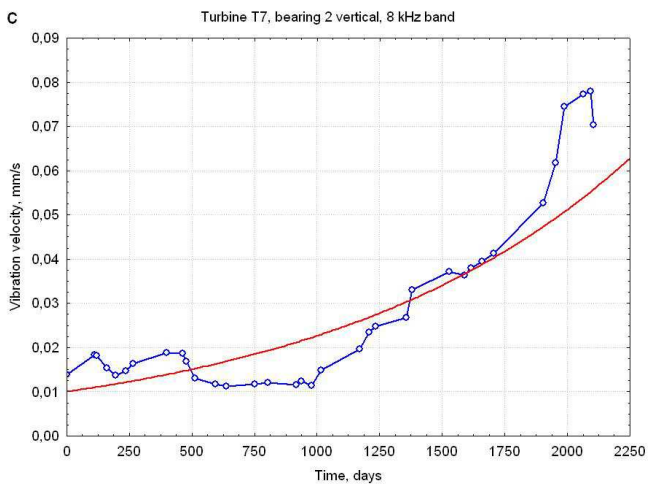

(c)

Fig. 7. (a) Linear fit slope vs. time: $230 \mathrm{MW}$ unit, front low-pressure turbine bearing, horizontal direction, $6.3 \mathrm{kHz}$ band; (b) the same, $200 \mathrm{MW}$ unit, low-pressure turbine casing rear/ right side, horizontal direction, $3.15 \mathrm{kHz}$ band; (c) vibration velocity vs. time: $200 \mathrm{MW}$ unit, high pressure/intermediate pressure bearing, vertical direction, $8 \mathrm{kHz}$ band. Data smoothing: peak trimming at $c=1.5$ followed by three-point averaging. Red line in (c) represents exponential fit.

Although quantitative assessment results should not be generalized over different turbine types, it has been estimated that, for components from the blade frequency range, vibration velocity vs. time plots with linear slope values below about $(10 \div 20) \times 10^{-6}(\mathrm{~mm} / \mathrm{s}) /$ day are typical for normal lifetime consumption (natural damage) with $\theta$ substantially lower than $\theta_{b}$. For the harmonic frequency range, the value of $10^{-4}(\mathrm{~mm} / \mathrm{s}) /$ day may be accepted as a very rough estimate. Accelerated damage may result in a value higher by an order of magnitude 
(cf. Fig.3). It has to be kept in mind, however, that in the harmonic range normalization of life cycles is mandatory.

\section{Statistical symptoms}

\subsection{Dispersion measures}

Up to this point, the deterministic approach has been employed. It may be argued that this is not compliant with the statistical nature of vibration generation mechanisms. What is more important, however, is the fact that statistical approach allows for eliminating problems resulting from the influences of control and interference. The basic idea may be summed up as 'if we cannot get rid of it, then try to make use of it'.

The main assumption in the statistical approach is that a symptom is a random variable rather than a deterministic function of machine condition parameters. Parameters of this random variable also depend on object condition and thus may be themselves accepted as symptoms (sometimes they are referred to as meta-symptoms, in order to stress that they are not directly measurable physical quantities). The idea of determining such symptoms is shown schematically in Fig.8.

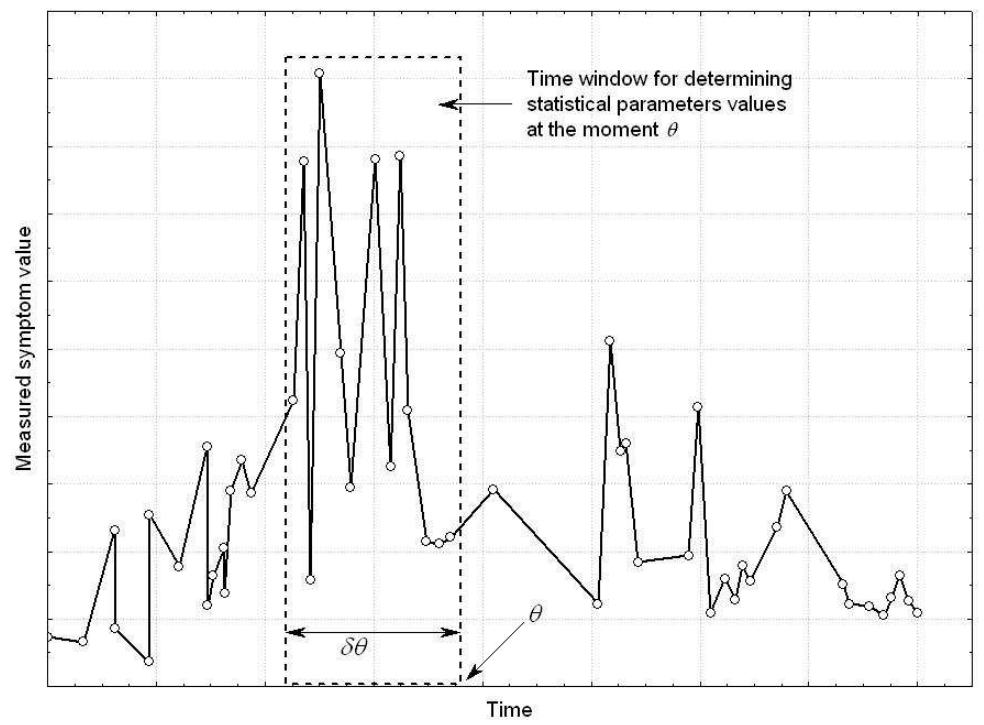

Fig. 8. The idea of statistical symptom determination: parameters pertaining to measured symptom value distribution are determined within a time window $\delta \theta$.

Obviously elements of the control and interference vectors are also random variables. Moreover, for a given turbine at some fixed location, it is reasonable to assume that statistical parameters of these random variables do not change with time, so each of them is characterized by a time-invariant probability distribution. Now, let us assume that we determine probability distribution of a vibration-based symptom $S$ (say, vibration velocity level in a given frequency band, measured in a given point) in a manner shown in Fig.8. If it can be shown that 


$$
\partial S / \partial R_{i}=f(\mathbf{X}) \text { and } / \text { or } \partial S / \partial Z_{i}=f(\mathbf{X}),
$$

then the distribution of $S$ will obviously change with condition parameters. Intuitively we may expect that with deteriorating technical condition both $\partial S / \partial R_{i}$ and $\partial S / \partial Z_{i}$ will increase as $\theta \rightarrow \theta_{b}$, i.e. $S$ shall be more and more sensitive to control and interference parameters. It can be shown on the basis of a suitably modified Energy Processor model that this is exactly the case (Gałka and Tabaszewski, 2011), providing that measurement errors are excluded. Thus, a measure of vibration level dispersion may be accepted as a diagnostic symptom.

Standard deviation $\sigma$ is the most commonly used dispersion measure. From the point of view of this application, it has two main deficiencies. First, normal distribution is tacitly assumed, which in general is not the case. Second, standard deviation is very sensitive to outliers, and obviously no data smoothing can be employed in estimating dispersion. Although standard deviation has yielded basically encouraging results (Gałka, 2008b), robust measures are far superior. Mean absolute difference between two consecutive measurement results $\Delta$ was first proposed (Gałka, 2008b) and $\Delta(\theta)$ time histories have been found much more regular and easier to interpret than those of $\sigma(\theta)$. Other possibilities include median absolute deviation about the median $m$, defined as

$$
m=\operatorname{Med}[S-\operatorname{Med}(S)],
$$

which in fact consists in centering the data around median rather than mean value, and interquartile range given by:

$$
q=Q_{3}(S)-Q_{1}(S)
$$

where $Q_{i}$ is the $i^{\text {th }}$ quartile:

$$
Q_{1}=F^{-1}(0.25), Q_{2}=F^{-1}(0.5), Q_{3}=F^{-1}(0.75),
$$

$F$ being the cumulative distribution function. Obviously, for a symmetrical distribution these two approaches are equivalent, but with a heavy-tailed distribution this is not the case. For the normal distribution, both $m$ and $q$ are constant multiples of $\sigma$.

Time window width $\delta$ is obviously a compromise. Larger $\delta$ yields better estimation of dispersion but it has to be kept in mind that the approach schematically shown in Fig.8 is in fact based on the assumption that

$$
\widehat{\wedge}_{i} X_{i}(\theta+\delta \theta) \approx X_{i}(\theta)
$$

If this condition is not fulfilled, centering data around any value 'averaged' over the entire time window becomes groundless. This is certainly the case when $\theta$ is close to $\theta_{b}$. In analyzing time series one should speak in terms of deviations from the trend rather than from some mean value corresponding to the entire time window. This in fact explains why $\Delta(\theta)$ yields better results, as differences between consecutive measurement results better represent such deviations. Another symptom may be thus proposed, in the form of

$$
\varepsilon=\frac{\sum_{i=1}^{n}\left[\left|S\left(\theta_{i}\right)-S_{t}\left(\theta_{i}\right)\right|\right]}{n},
$$


where $i$ is the number of data points contained in the time window, $S\left(\theta_{i}\right)$ are consecutive symptom value readings and $S_{t}(\theta)$ represents symptom trend estimated for the entire period under consideration.

Comparison of these five dispersion measures is shown in the example presented in Fig.9, which refers to a natural damage (last measurement was performed shortly before rotor
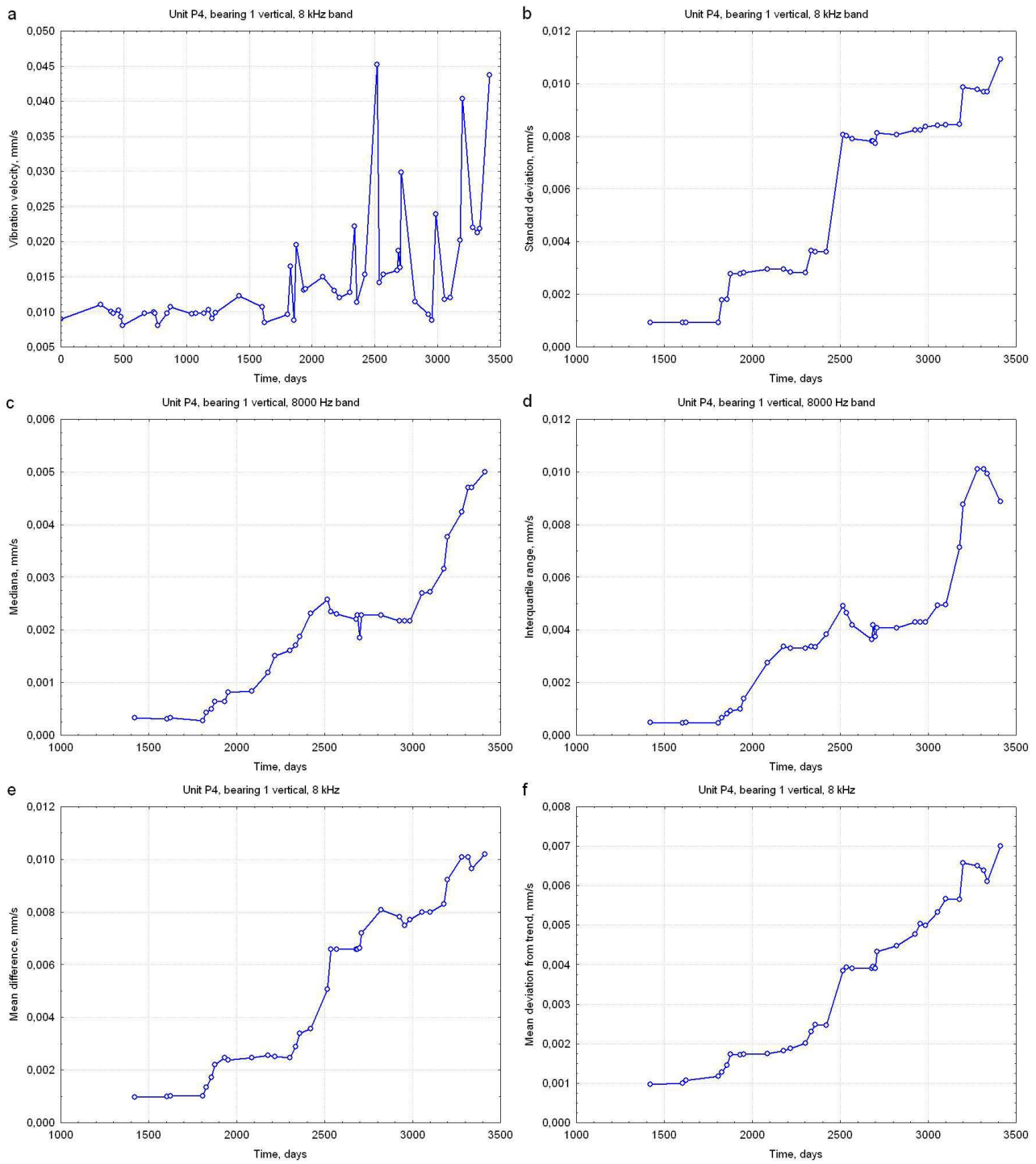

Fig. 9. K-200 unit, front high-pressure turbine bearing, vertical direction, $8 \mathrm{kHz}$ band.

(a) symptom time history, (b) $\sigma(\theta)$, (c) $m(\theta),(\mathrm{d}) q(\theta),(\mathrm{e}) \Delta(\theta)$, (f) $\varepsilon(\theta)$; data window containing 20 measurements. 
replacement). It is easily seen that they all increase with $\theta$, almost monotonically, but $\sigma(\theta)$ is obviously influenced by outliers and hence is of 'step-like' form. Both $m(\theta)$ and $q(\theta)$ are more regular, but certainly $\Delta(\theta)$ and $\varepsilon(\theta)$ are superior; in particular, the latter is most regular and almost perfectly monotonic. The 'dynamics' of these symptoms is also noteworthy: during the period covered by observation they increase roughly by one order of magnitude. They may be thus considered highly sensitive to lifetime consumption. It may also be noted that a marked increasing tendency starts well before rotor replacement (about four years). Symptoms of this type may thus provide an 'early warning', with a lead long enough e.g. to re-schedule maintenance or purchase replacement parts.

\subsection{Correlation measures}

The use of a correlation measure in vibration-based condition assessment is twofold. First, we may check the very existence of correlation or, more precisely, determine if it is 'weak' or 'strong'. This may be very useful, because - as already noted - in steam turbines several possible malfunctions sometimes produce similar changes of vibration characteristics. Such approach is thus applicable in qualitative diagnostics. Second, we may study how a correlation measure changes with time and utilize the results for a quantitative diagnosis.

The most commonly used measure of correlation is the Pearson product-moment correlation coefficient $r$, given by the normalized covariance

$$
r=\frac{E\left\{\left(S_{1}-\eta_{1}\right)\left(S_{2}-\eta_{2}\right)\right\}}{\sqrt{E\left\{\left(S_{1}-\eta_{1}\right)^{2}\right\} E\left\{\left(S_{2}-\eta_{2}\right)^{2}\right\}}},
$$

where $E$ denotes expected value and

$$
\eta_{1}=E\left(S_{1}\right), \eta_{2}=E\left(S_{2}\right) .
$$

This measure is very sensitive to outliers (see e.g. Maronna, Martin and Yohai, 2006), but is often sufficient for a qualitative diagnosis. The basic idea stems from the fact that if two symptoms can be shown to be correlated, we may infer that they are dependent, i.e. that their changes have been caused by the same condition parameter. The reverse is not true: if two random variables are not correlated, this does not imply that they are independent.

Fig.10 shows two vibration time histories recorded with a $200 \mathrm{MW}$ turbine that suffered an intermediate-pressure rotor failure and secondary fracture of steam guiding fences. Manifestation of this failure in vibration patterns was quite complex. It may be noted, however, that before repair both these components tended to increase simultaneously. Several other components from the blade frequency range - up to about $2 \mathrm{kHz}$ - behaved in a similar manner. We may thus suspect that comparatively high level of the $4 \times f_{0}$ component was a result of the fluid-flow system failure. This is corroborated by correlation analysis; for $23 \%$ $\mathrm{CPB}$ spectra bands from $800 \mathrm{~Hz}$ to $2 \mathrm{kHz}$ coefficients of correlation with the $4 \times f_{0}$ component ranged from $r=0.689$ to $r=0.912$, while for two other turbines of the same type $|r|$ was below 0.2 (in several cases negative). Shortly after the repair the $4 \times f_{0}$ component increased again, eventually reaching even substantially higher level; this time, however, 
there is virtually no correlation with the blade components, $r$ being about -0.1 . The root cause was thus different. ${ }^{3}$
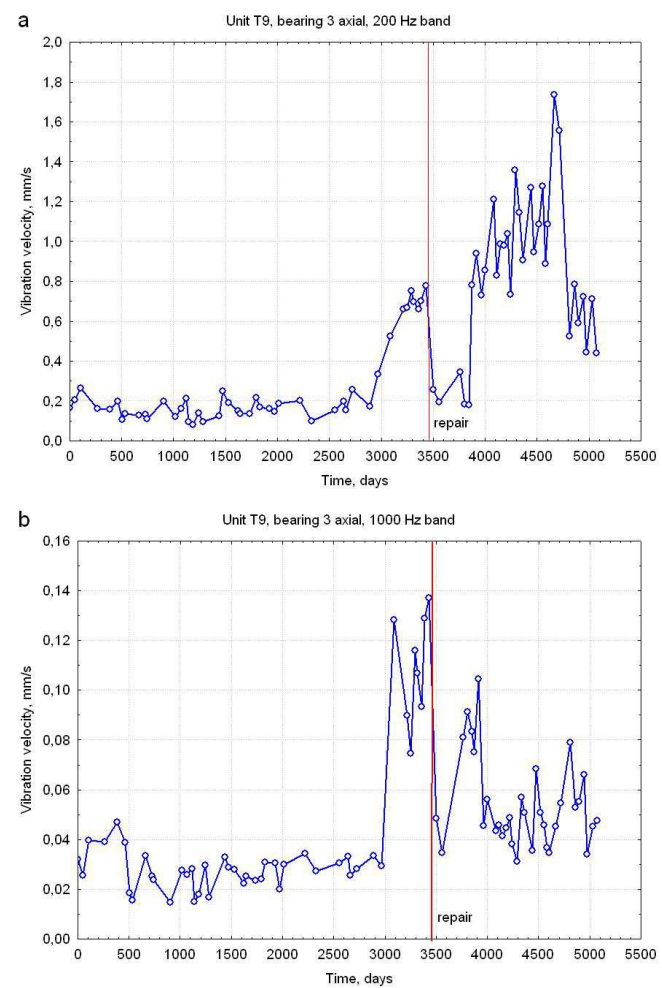

Fig. 10. Time histories of vibration amplitudes: K-200 unit, rear intermediate-pressure turbine bearing, axial direction, $4 \times f_{0}$ (a) and $1000 \mathrm{~Hz}$ (b) components. Vertical lines indicate repair.

In addition to being sensitive to outliers, the Pearson correlation coefficient is deficient in that a linear relation is assumed. Both above-mentioned disadvantages may be eliminated or at least alleviated to some extent by using non-linear and more robust measures of correlation. These include the Kendall rank correlation coefficient $\tau$, given by

$$
\tau=1-\frac{2 d_{\Delta}}{N(N-1)}
$$

and Spearman rank correlation coefficient $\rho$, given by

$$
\rho=1-\frac{6 \sum d_{i}^{2}}{N\left(N^{2}-1\right)} .
$$

${ }^{3}$ Detailed case study may be found in (Gałka, 2008a) 
In these formulae, $N$ is the number of scores (elements) in two data samples, $d_{\Delta}$ denotes symmetric difference distance and $d_{i}$ are differences between individual ranks. It should be noted here that both $\tau$ and $\rho$ are calculated on the basis of ranks rather than standard deviations and therefore more suitable for analyzing time series (Salkind, 2007). They are thus more appropriate when dealing with correlation as a function of $\theta$.

As mentioned earlier, for a rapidly developing damage one should speak in terms of a deviation from the trend than of some mean or expected value. We may therefore, as suggested in (Gałka, 2011a), introduce yet another correlation measure, tentatively termed 'modified Parsons coefficient' $r$ '. Using the notation from Eqs.(30) and (31), $r$ ' is given by

$$
r^{\prime}=\frac{E\left\{\left(S_{1}-S_{t 1}\right)\left(S_{2}-S_{t 2}\right)\right\}}{\sqrt{E\left\{\left(S_{1}-S_{t 1}\right)^{2}\left(S_{2}-S_{t 2}\right)^{2}\right\}}} .
$$

Let us assume that lifetime consumption degree $D=\theta / \theta_{b}$ is the only condition parameter that is taken into account. Then Eq.(9) for a given symptom $S$ may be rewritten as

$$
S=f\left(D, R_{1}, R_{2}, \ldots, R_{k}, Z_{1}, Z_{2}, \ldots, Z_{m}\right) .
$$

Within the framework of the Energy Processor model, the influence of $D$ on $S$ is purely deterministic and $S(D)$ is a monotonically increasing function. As $D$ approaches unity, both $S$ and $d S / d D$ tend to infinity (cf. Eq(14)), so equal increments of $D$ will result in increasing increments of $S$ :

$$
D \rightarrow 1 \Rightarrow \Delta S=S(D+\Delta D)-S(D) \rightarrow \infty \quad(\Delta D=\text { const. }),
$$

and this will hold for all symptoms. Correlation is thus expected to increase with $D$, as for any two symptoms $S_{j}$ and $S_{k}$ both will, to a growing extent, be dominated by $D$ rather than other factors and thus become more deterministic with respect to $D$. Speaking in a descriptive manner, Eq.(35) may be viewed as revealing a competition between the random (represented by $R_{i}$ and $Z_{i}$ ) and the deterministic (represented by $D$ ). The above argumentation suggests that for $D \rightarrow 1$ the latter should prevail and consequently a measure of correlation should increase in value. This phenomenon has been termed the 'Old Man Syndrome'. 4

Fig.11 shows comparison of the above four correlation measures plotted against time for the same unit as in Fig.9 (albeit for different frequency bands). All plots exhibit a more or less pronounced 'saddle', which was found to have resulted from an overhaul which 'decorrelated' the symptoms to a certain extent. The terminal increasing section is, however, evident.

Due to a large number of vibration-based symptoms generated by a typical multi-stage steam turbine, the number of pairs to be analyzed in terms of correlation is large, of the order of a few dozen or more. It is, however, possible to select those with the highest content

${ }^{4}$ To the author's best knowledge, this term has been first used in the context of technical diagnostics by Cempel (see Cempel, 1991). 

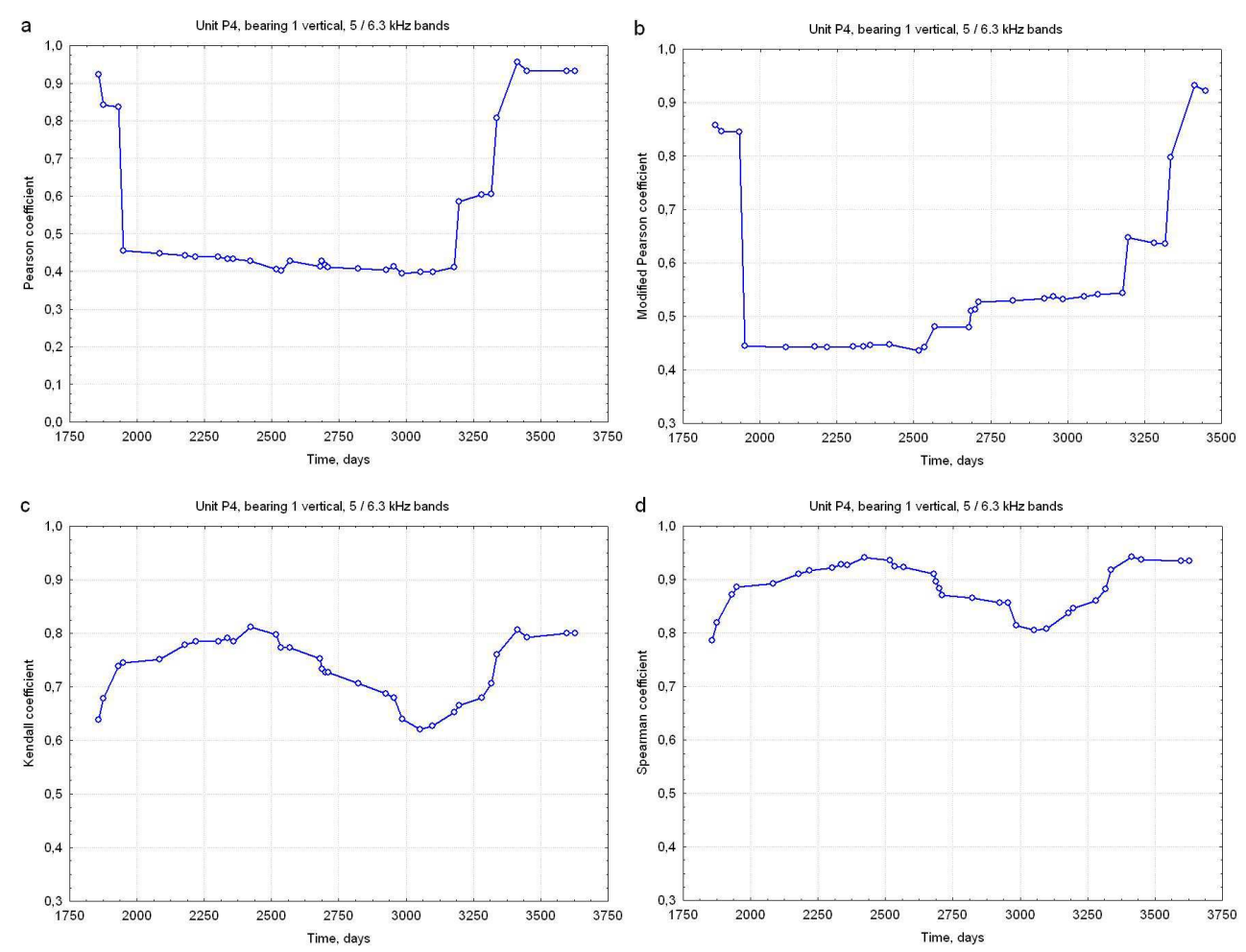

Fig. 11. Plots of Pearson (a), modified Pearson (b), Kendall (c) and Spearman (d) correlation coefficients: $200 \mathrm{MW}$ unit, front high-pressure turbine bearing, vertical direction, $5 \mathrm{kHz}$ and $6.3 \mathrm{kHz}$ bands. Data window containing 25 measurements.

of diagnostic information. Such selection may employ the Singular Value Decomposition method, known from linear algebra (see e.g. Cempel, 2003). This approach has been applied to a number of steam turbines and results have been found very encouraging (Gałka, 2011a). In general, components generated by rotor stages are more informative in this respect than those generated by bladed diaphragms. Best results have been obtained with high-pressure turbines; this is not particularly surprising, due to high temperature and pressure, which contribute to accelerated lifetime consumption.

\section{Conclusion}

Steam turbines, which are of vital importance for any economy, have always been at the leading edge of technical diagnostics development. A variety of vibration monitoring systems is available on a commercial scale, usually tailored to individual needs. Some of them are referred to as 'diagnostic systems', which is not always strictly true, as many merely provide data for diagnostic reasoning.

In general, qualitative diagnostics is currently based on well-established procedures and rules, especially for harmonic components. Quantitative condition assessment seems to be at 
an earlier development stage, at least when it comes to practical applications. Its importance is, however, appreciated, in view of introducing predictive maintenance. As a turbine model suitable for theoretical determination of quantitative diagnostic relations still remains to be developed, much of the work in this field employs empirical data. It seems justified to say that reliable forecasting of technical condition development is currently the major challenge that faces specialists in this field throughout the world.

\section{Acknowledgments}

The author wishes to express his deep gratitude to Prof. Czesław Cempel and Prof. Stanisław Radkowski for numerous discussions and inspiration that have been invaluable throughout his professional career in the field of technical diagnostics. The memory of late Prof. Zenon Orłowski, who had been author's teacher and friend until his untimely death, is gratefully acknowledged.

\section{References}

Bachschmid, N., Pennacchi, P. and Tanzi, E. (2010). Cracked Rotors. A Survey on Static and Dynamic Behaviour Including Modelling and Diagnosis. Springer, ISBN 978-3-64201484-0, Berlin-Heidelberg, Germany

Bently, D.E. and Hatch, C.T. (2002). Fundamentals of Rotating Machinery Diagnostics, Bently Pressurized Bearings Press, ISBN 0-9714081-0-6, Minden, USA

Cempel, C. (1991). Vibroacoustic Condition Monitoring, Ellis Horwood, ISBN 0-13-931718-X, New York, USA

Cempel, C., Natke, H.G. and Yao J.T.P. (2000). Symptom reliability and hazard for systems condition monitoring, Mechanical Systems and Signal Processing, vol.14, No.3 (2000) pp. 495-505, ISSN 0888-3270

Cempel, C. (2003). Multidimensional Condition Monitoring of Mechanical Systems in Operation. Mechanical Systems and Signal Processing, vol.17, No.6 (2003) pp. 1291-1303, ISSN 0888-3270

Crocker, J. (2003). Prognostics in Aero-Engines, Proceedings of the $16^{\text {th }}$ International Congress COMADEM 2003, pp. 145-154, ISBN 91-7636-376-7, Växjö, Sweden, August 27-29, 2003

Gałka, T. (1999). Application of energy processor model for diagnostic symptom limit value determination in steam turbines. Mechanical Systems and Signal Processing, vol.13, No.5 (1999) pp.757-764, ISSN 0888-3270

Gałka, T. (2001). Influence of Turbine Load on Vibration Patterns and Symptom Limit Value Determination Procedures, Proceedings of the $14^{\text {th }}$ International Conference COMADEM 2001, pp. 967-976, ISBN 008 0440363, Manchester, UK, September 4-6, 2001

Gałka, T. (2008a). Correlation-Based Symptoms in Rotating Machines Diagnostics, Proceedings of the 21 International Congress COMADEM 2008, pp. 213-226, ISBN 97880-254-2276-2, Praha, Czech Republic, June 11-13, 2008

Gałka, T. (2008b). Statistical Vibration-Based Symptoms in Rotating Machinery Diagnostics. Diagnostyka, vol. 2(46)/2008, pp. 25-32, ISSN 1641-6414 
Gałka, T. (2009a). Large Rotating Machines, In: Encyclopedia of Structural Health Monitoring, C.Boller, F.Chang and Y.Fujino (Ed.), 2443-2456, Wiley, ISBN 978-0-47-006162-6, Chichester, UK

Gałka, T. (2009b). Rotor Bow in a 230 MW Steam Turbine: A Case Study, Proceedings of the $6^{\text {th }}$ International Conference on Condition Monitoring and Machine Failure Prevention Technologies, pp. 1053-1063, Dublin, Ireland, June 23-25, 2009 (CD-ROM edition)

Gałka, T. and Tabaszewski, M. (2011). An Application of Statistical Symptoms in Machine Condition Diagnostics, Mechanical Systems and Signal Processing, vol.25, No.1 (2011) pp. 253-265, ISSN 0888-3270

Gałka, T. (2011a). The 'Old Man Syndrome' in Machine Lifetime Consumption Assessment, Proceedings of the $8^{\text {th }}$ International Conference on Condition Monitoring and Machine Failure Prevention Technologies, paper No. 108, Cardiff, UK, June 20-22, 2011 (CDROM edition)

Gałka, T. (2011b). Influence of Load and Interference in Vibration-Based Diagnostics of Rotating Machines, Advances and Applications in Mechanical Engineering and Technology, vol. 3, No. 1/2 (2011), pp. 1-19, ISSN 0976-142X, available from http:/ / scientificadvances.co.in/index.php?cmd=artical\&j=7\&su=66

Kiciński, J. (2006). Rotor Dynamics, IFFM Publishers, ISBN 83-7204-542-9, Gdańsk, Poland

Martin, K.F. (1994). A Review by Discussion of Condition Monitoring and Fault Diagnosis in Machine Tools. Int. Journal of Machine Tools and Manufacture, vol. 34 (1994), pp. 527551, ISSN 0890-6955

Maronna, R.A., Martin, R.D. and Yohai, V.J. (2006) Robust Statistics. Theory and Methods, John Wiley \& Sons, ISBN 0-470-01092-4, Chichester, UK

Morel, J. (1992). Vibration des Machines et Diagnostic de Leur État Mécanique, Eyrolles, ISBN 0399-4198, Paris, France

Natke, H.G. and Cempel, C. (1997). Model-Aided Diagnosis of Mechanical Systems, Springer, ISBN 978-3540610656, Berlin-Heidelberg, Germany

Neyman, J. and Pearson E.S. (1933). On the problem of the most efficient tests of statistical hypotheses. Philosophical Transactions of the Royal Society of London, Ser. A, 231, pp. 289-337

Orłowski, Z. and Gałka, T. (1995). Excessive Vibration of a Small Steam Turbine: Diagnosis and Remedy, Proceedings of the Inter-Noise'95 International Congress, pp. 1133-1137, ISBN 0-931784-32-8, Newport Beach, USA, July 10-12, 1995

Orłowski, Z. and Gałka, T. (1997). Determination of Diagnostic Symptom Limit Values for Steam Turbines, Proceedings of the Condition Monitoring'97 International Conference, pp. 247-253, ISBN 7-118-01719-1, Xi' an, China, March 24-26, 1997

Orłowski, Z. and Gałka, T. (1998). Vibrodiagnostics of Steam Turbines in the Blade Frequency Range, Proceedings of the COMADEM 98 International Conference, pp. 683692, ISBN 0-7326-2027-9, Monash University, Australia, December 8-11, 1998

Orłowski, Z. (2001). Diagnostyka w życiu turbin parowych, WNT, ISBN 83-204-2642-1, Warsaw, Poland

Radkowski, S. (1995). Low-Energy Components of Vibroacoustic Signal as the Basis for Diagnosis of Defect Formation. Machine Dynamics Problems, vol. 12 (1995), ISSN 0239-7730

Randall, R.B. (2011). Vibration-Based Condition Monitoring, Wiley, ISBN 978-0-470-74785-8, Chichester, UK 
Salkind, N.J. (Ed.) (2007). Encyclopedia of Measurements and Statistics, SAGE Publications, ISBN 978-1-412-91611-0, Thousand Oaks, USA

Traupel, W. (2000). Thermische Turbomaschinen. Zweiter Band: Geanderte Betriebsbedingungen, Regelung, mechanische Probleme, Temperaturprobleme, ISBN 978-3-540-67376-7, Springer, Berlin 


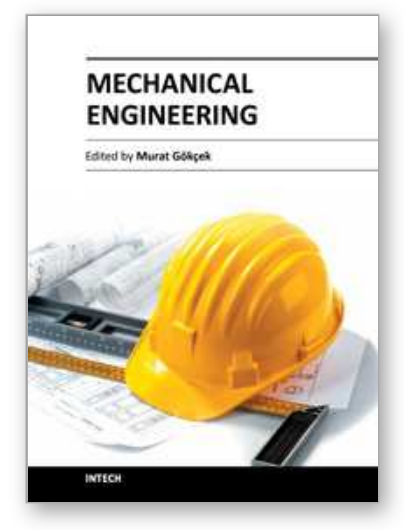

\author{
Mechanical Engineering \\ Edited by Dr. Murat Gokcek
}

ISBN 978-953-51-0505-3

Hard cover, 670 pages

Publisher InTech

Published online 11, April, 2012

Published in print edition April, 2012

The book substantially offers the latest progresses about the important topics of the "Mechanical Engineering" to readers. It includes twenty-eight excellent studies prepared using state-of-art methodologies by professional researchers from different countries. The sections in the book comprise of the following titles: power transmission system, manufacturing processes and system analysis, thermo-fluid systems, simulations and computer applications, and new approaches in mechanical engineering education and organization systems.

\title{
How to reference
}

In order to correctly reference this scholarly work, feel free to copy and paste the following:

Tomasz Gałka (2012). Vibration-Based Diagnostics of Steam Turbines, Mechanical Engineering, Dr. Murat Gokcek (Ed.), ISBN: 978-953-51-0505-3, InTech, Available from:

http://www.intechopen.com/books/mechanical-engineering/vibration-based-diagnostics-of-steam-turbines

\section{INTECH}

open science | open minds

\author{
InTech Europe \\ University Campus STeP Ri \\ Slavka Krautzeka 83/A \\ 51000 Rijeka, Croatia \\ Phone: +385 (51) 770447 \\ Fax: +385 (51) 686166 \\ www.intechopen.com
}

\author{
InTech China \\ Unit 405, Office Block, Hotel Equatorial Shanghai \\ No.65, Yan An Road (West), Shanghai, 200040, China \\ 中国上海市延安西路65号上海国际贵都大饭店办公楼 405 单元 \\ Phone: +86-21-62489820 \\ Fax: +86-21-62489821
}


(C) 2012 The Author(s). Licensee IntechOpen. This is an open access article distributed under the terms of the Creative Commons Attribution 3.0 License, which permits unrestricted use, distribution, and reproduction in any medium, provided the original work is properly cited. 